\title{
Pre- and Posttranslational Regulation of $\beta$-Endorphin Biosynthesis in the CNS: Effects of Chronic Naltrexone Treatment
}

\author{
David M. Bronstein, Nicola C. Day, *Howard B. Gutstein, Keith A. Trujillo, and Huda Akil \\ Mental Health Research Institute and *Department of Anesthesiology, University of Michigan, Ann Arbor, Michigan, U.S.A.
}

\begin{abstract}
There appear to be two anatomically distinct $\beta$ endorphin $(\beta \mathrm{E})$ pathways in the brain, the major one originating in the arcuate nucleus of the hypothalamus and a smaller one in the area of the nucleus tractus solitarius (NTS) of the caudal medulla. Previous studies have shown that these two proopiomelanocortin (POMC) systems may be differentially regulated by chronic morphine treatment, with arcuate cells down-regulated and NTS cells unaffected. In the present experiments, we examined the effects of chronic opiate antagonist treatment on $\beta \mathrm{E}$ biosynthesis across different CNS regions to assess whether the arcuate POMC system would be regulated in the opposite direction to that seen after opiate agonist treatment and to determine whether different $\beta E$-containing areas might be differentially regulated. Male adult rats were administered naltrexone (NTX) by various routes for 8 days (subcutaneous pellets, osmotic minipumps, or repeated intraperitoneal injections). Brain and spinal cord regions were assayed for total $\beta \mathrm{E}$-ir, different molecular weight immunoreactive $\beta$-endorphin ( $\beta$ E-ir) peptides, and POMC mRNA. Chronic NTX treatment, regardless of the route of administration, reduced total $\beta \mathrm{E}$-ir concentrations by $30-40 \%$ in diencephalic areas (the arcuate nucleus, the remaining hypothalamus, and the thalamus) and the midbrain, but had no effect on
\end{abstract}

$\beta \mathrm{E}$-ir in the NTS or any region of the spinal cord. At the same time, NTX pelleting increased POMC mRNA levels in the arcuate to $\sim 140 \%$ of control values. These data suggest that arcuate POMC neurons are up-regulated after chronic NTX treatment (whereas NTS and spinal cord systems remain unaffected) and that they appear to be under tonic inhibition by endogenous opioids. Chromatographic analyses demonstrated that, after chronic NTX pelleting, the ratio of full length $\beta \mathrm{E}_{1-31}$ to more processed $\beta \mathrm{E}$-ir peptides (i.e., $\beta \mathrm{E}_{1-27}$ and $\beta \mathrm{E}_{1-26}$ ) tended to increase in a dose-dependent manner in diencephalic areas. Because $\beta \mathrm{E}_{1-31}$ is the only POMC product that possesses opioid agonist properties, and $\beta \mathrm{E}_{1-27}$ has been posited to function as an endogenous anatgonist of $\beta \mathrm{E}_{1-31}$, the NTX-induced changes in the relative concentrations of $\beta \mathrm{E}_{1-31}$ and $\beta \mathrm{E}_{1-27} / \beta \mathrm{E}_{1-26}$ may represent a novel regulatory mechanism of POMC cells to alter the opioid signal in the synapse. Key Words: OpioidsOpiate antagonist-Proopiomelanocortin- $\beta$-Endorphin processing-Proopiomelanocortin mRNA-Endogenous opioids. Bronstein D. M. et al. Pre- and posttranslational regulation of $\beta$-endorphin biosynthesis in the CNS: Effects of chronic naltrexone treatment. $J$. Neurochem. 60, 40-49 (1993).
Although there is abundant behavioral and pharmacological evidence to suggest an involvement of the endogenous opioid peptide $\beta$-endorphin $(\beta \mathrm{E})$ in various physiological functions, there is only minimal information regarding the regulation of $\beta \mathrm{E}$ biosynthesis in the CNS. Such information is important for understanding the molecular mechanisms that subserve $\beta \mathrm{E}$-mediated physiological responses and for identifying functional roles of $\beta \mathrm{E}$ peptides. In the present studies, we sought to address two basic issues regarding the regulation of neuronal $\beta \mathrm{E}$ systems. The first issue relates to how $\beta \mathrm{E}$ biosynthesis is altered by changes in neuronal stimulation and the second issue concerns whether these changes affect all proopiomelanocortin
Received March 9, 1992; revised manuscript received June 3, 1992; accepted June 3, 1992.

Address correspondence and reprint requests to Dr. D. Bronstein at Laboratory of Molecular and Integrative Neuroscience (LMIN), National Institute of Environmental Health Sciences (NIEHS), P. O. Box 12233, MD 14-06, Research Triangle Park, NC 27709, U.S.A.

Abbreviations used: ACTH, adrenocorticotropin; BSA, bovine serum albumin; CSC, cervical spinal cord; DYN, dynorphin; $\beta \mathrm{E}$, $\beta$-endorphin; $\beta \mathrm{E}$-ir, immunoreactive $\beta$-endorphin; GITC, guanidium isothiocyanate; $\beta$-LPH, $\beta$-lipotropin; LSC, lumbosacral spinal cord; $\alpha$-MSH, $\alpha$-melanotropin; NTS, nucleus tractus solitarius; NTX, naltrexone; POMC, proopiomelanocortin; Pro-DYN, prodynorphin; RIA, radioimmunoassay; SDS, sodium dodecyl sulfate; TSC, thoracic spinal cord. 
(POMC) neurons in the CNS or whether there are regional differences in how $\beta \mathrm{E}$ biosynthesis is regulated.

Like most neuropeptides, $\beta \mathrm{E}$ is synthesized as part of a larger precursor protein, POMC (Mains et al., 1977; Roberts and Herbert, 1977a; Nakanishi et al., 1979). This adds a great deal of flexibility and complexity to POMC's regulation in the following two respects: (1) POMC-derived peptides outside of the $\beta \mathrm{E}$ domain [e.g., adrenocorticotropin (ACTH), $\alpha$-melanotropin $(\alpha$-MSH), $\beta$-lipotropin $(\beta$-LPH)] may have interactive effects with $\beta \mathrm{E}$, and (2) within the $\beta \mathrm{E}$ domain itself, a number of chemically modified forms of $\beta E$-like peptides are cosynthesized, each with unique physiological/functional properties that may neutralize or antagonize $\beta \mathrm{E}_{1-31}$ effects. The biosynthesis of $\beta \mathrm{E}$ from POMC involves a series of proteolytic cleavages and posttranslational modifications that first produce $\beta-\mathrm{LPH}$ and subsequently $\beta \mathrm{E}_{1-31}$, the 31 amino acid sequence at the $\mathrm{COOH}$-terminal end of $\beta$-LPH (Bradbury et al., 1976; Chretien et al., 1976; Mains et al., 1977; Roberts and Herbert, 1977b). $\beta \mathrm{E}_{1-31}$ is subject to further proteolysis at the Lys-Lys pair $\left(\beta \mathrm{E}_{28}-\beta \mathrm{E}_{29}\right)$, resulting in $\beta \mathrm{E}_{1-27}$, which in turn can be cleaved to form $\beta \mathrm{E}_{1-26}$. Each of these three forms of $\beta \mathrm{E}$ (i.e., the 26, 27, and 31 amino acid forms) can be further modified by acetylation at the $\mathrm{NH}_{2}$-terminus. Interestingly, only $\beta \mathrm{E}_{1-31}$ possesses properties characteristic of classical opiates. Conversion of $\beta \mathrm{E}_{1-31}$ to $\mathrm{NH}_{2}$ - and $\mathrm{COOH}$-terminal modified forms results in peptides that have no effect, or are antagonists, at opioid receptors. Thus, changes in the relative concentrations of different immunoreactive $\beta$-endorphin $(\beta \mathrm{E}$-ir) peptides could cause significant changes in the opioid "message" transmitted across a synapse.

The second critical issue to consider in studying the regulation of $\beta \mathrm{E}$-containing neurons relates to $\beta \mathrm{E}$ 's localization in anatomically or functionally distinct neuronal systems. The distribution of POMC-containing cells in the CNS can be described in terms of rostral and caudal systems. The major POMC system is the rostral one, with cell bodies located in and around the arcuate nucleus of the mediobasal hypothalamus and axonal fibers projecting to diverse brain regions (e.g., various hypothalamic and thalamic nuclei, the amygdala, septum, and midbrain) (Watson et al., 1977, 1978; Bloch et al., 1978; Bloom et al., 1978; Nilaver et al., 1979). The smaller caudal POMC system has perikarya scattered in the vicinity of the nucleus tractus solitarius (NTS) in the medulla oblongata (Joseph et al., 1983; Schwartzberg and Nakane, 1983; Bronstein et al., 1992). This cell cluster does not appear to have a significant number of rostrally projecting fibers; rather, POMC NTS neurons are posited to project locally within the brainstem or possibly caudally into the spinal cord (Palkovits and Eskay, 1987; Palkovits et al., 1987; Joseph and Michael, 1988). There are significant differences across different CNS areas in the extent to which POMC is pro- cessed to $\beta \mathrm{E}$-ir peptide products. In general, processing is greatest in the rostral POMC system (where $\beta$ LPH comprises less than $5 \%$ and $\beta \mathrm{E}_{1-31} \sim 60 \%$ of the total $\beta E$-ir), least in the spinal cord (larger molecular weight $\beta \mathrm{E}$-ir species represent $\leq 60 \%$ of total $\beta \mathrm{E}$-ir and $\beta \mathrm{E}_{1-31}$ as little as $10 \%$ ), and intermediate in the NTS (Zakarian and Smyth, 1982; Dores et al., 1986; Emeson and Eipper, 1986; Gianoulakis and Angelogianni, 1989; Gutstein et al., 1992).

Much of what is currently known about the regulation of $\beta \mathrm{E}$ biosynthesis has been derived from studies in the pituitary gland. Results from these studies have demonstrated the following two general principles: (1) Levels of biosynthesis appear coupled to levels of peptide release, and (2) different biosynthetic mechanisms (e.g., transcriptional, translational, posttranslational) are invoked in a time-dependent fashion in the process of the cellular coordination of its secretion and biosynthetic rates. For example, after acute stimulation, POMC precursor is translated and processed more rapidly than normal, in an apparent short-term attempt to replenish depleted peptide stores; after chronic stimulation, levels of POMC mRNA increase, thereby providing cells with larger, long-term biosynthetic capacity (Akil et al., 1985; Shiomi et al., 1986). Recent data suggest that regulatory principles from the pituitary are generalizable to the CNS. For example, we (Bronstein et al., 1990) and others (Mocchetti and Costa, 1986; Mocchetti et al., 1989) have shown that chronic morphine treatment causes timedependent alterations in multiple parameters of $\beta \mathrm{E}$ biosynthesis in a manner suggesting that morphine inhibits $\beta \mathrm{E}$ release and biosynthesis in hypothalamic POMC neurons. Although morphine treatment inhibited hypothalamic POMC neurons, it had no effect on $\beta \mathrm{E}$-ir peptide concentrations in the NTS, and increased $\beta \mathrm{E}$-ir levels in the spinal cord (Gutstein et al., 1990; Bronstein et al., in preparation). These data suggest that opiates modulate $\beta \mathrm{E}$ biosynthesis in a region-specific manner in the CNS. The goal of the present studies was to examine the effects of chronic naltrexone (NTX) treatment on $\beta \mathrm{E}$ biosynthesis. In light of morphine's inhibitory effects on POMC neurons, it was of particular interest to determine whether opiate antagonist treatment would up-regulate $\beta \mathrm{E}$ biosynthesis, thereby implying that POMC neurons are tonically inhibited by endogenous opioids. We were also interested in finding out if NTX would affect $\beta \mathrm{E}$ biosynthesis in a region-specific manner, as was the case with morphine.

\section{MATERIALS AND METHODS}

\section{Animals}

Male Sprague-Dawley rats (Charles River Co., Wilmington, MA, U.S.A.), weighing $220-250 \mathrm{~g}$ at the start of the experiments, were maintained in groups of five to six per cage in an environmentally controlled room (12-h light/ 
dark cycle, lights on at $0600 \mathrm{~h}$ ) with free access to food and water.

\section{Drug treatments}

Animals received NTX via three different routes of administration. In the first experiment, animals lightly anesthetized with ether were implanted subcutaneously between the scapula with two NTX (10 or $30 \mathrm{mg} /$ pellet) or placebo (containing Avicel PH-102, magnesium stearate, silicon dioxide, and water) pellets (provided courtesy of the National Institute of Drug Addiction). After 8 days, animals were killed by decapitation and the following CNS regions were dissected: arcuate, hypothalamus minus the arcuate, thalamus, septum, amygdala, midbrain, and caudal medulla (including the NTS). Spinal cords were divided into cervical (CSC), thoracic (TSC), and lumbosacral (LSC) regions. In the second experiment, anesthetized animals were implanted subcutaneously with osmotic minipumps (Alzet, Palo Alto, CA, U.S.A.), which released solutions of either NTX $(70 \mathrm{mg} / \mathrm{ml})$ or distilled water at a rate of $1 \mu \mathrm{l} / \mathrm{h}$. Animals were killed after 8 days and hypothalami (including the arcuate nucleus) were collected. In the third experiment, animals received daily subcutaneous injections of NTX $(2$, 10 , or $20 \mathrm{mg} / \mathrm{kg}$ ) or saline for 7 days. Twenty-four hours after the last injection, animals were killed and hypothalami (including the arcuate) were removed. All tissues were frozen immediately on dry ice and stored at $-80^{\circ} \mathrm{C}$ until assayed.

\section{Tissue extractions}

POMC peptides and mRNA were extracted from the same tissue using a modified guanidium isothiocyanate (GITC) extraction method (Cathala et al., 1983). After homogenization in GITC buffer $(5.0 \mathrm{M}$ GITC, $8 \%$ mercaptoethanol, $10 \mathrm{~m} M$ EDTA, $50 \mathrm{~m} M$ Tris, $\mathrm{pH} 7.5$ ), 6 volumes of $4 \mathrm{MLiCl}$ was added and RNA was precipitated overnight at $4^{\circ} \mathrm{C}$. After centrifugation, RNA and peptides were separated into pellet and supernatant phases, respectively. The supernatant was acidified and peptides extracted over C-18 Sep-Pak columns (Waters, Milford, MA, U.S.A.). The SepPak eluant was dried down, then resuspended in $1 \%$ formic acid containing $0.01 \%$ bovine serum albumin (BSA). The RNA pellets were resuspended in a buffer [ $50 \mathrm{~m} M$ Tris, $\mathrm{pH}$ $7.5,5 \mathrm{mM}$ EDTA, $0.5 \%$ sodium dodecyl sulfate (SDS)] containing $150 \mu \mathrm{g} / \mathrm{ml}$ of proteinase $\mathrm{K}$ and incubated for $1 \mathrm{~h}$ at $43^{\circ} \mathrm{C}$. RNA was extracted twice with phenol/chloroform/ isoamyl alcohol (50:50:1, by vol). One-tenth volume of $3 M$ sodium acetate and 2.5 volumes of $100 \%$ ethanol were added and RNA was precipitated at $-20^{\circ} \mathrm{C}$.

\section{Peptide quantitation}

Total $\beta \mathrm{E}$-ir was determined in the crude extracts of individual animals by radioimmunoassay (RIA) using an antibody directed primarily against $\beta \mathrm{E}_{17-27}$ (Akil et al., 1979). Samples were resuspended in RIA buffer ( $150 \mathrm{~m} M$ sodium phosphate, $1 \% \mathrm{NaCl}, 0.1 \% \mathrm{BSA}$, final $\mathrm{pH} 8.2$ ) and were quantitated relative to a camel $\beta \mathrm{E}_{1-31}$ standard curve. Using a primary antibody dilution of $1: 40,000$ and ${ }^{125} \mathrm{I}-N$-acetyl$\beta \mathrm{E}_{1-27}$ as the trace, the antibody was completely cross-reactive with $\beta$-LPH, $\beta \mathrm{E}_{1-31}, \beta \mathrm{E}_{1-27}, \beta \mathrm{E}_{1-26}$, and their $N$-acetylated derivatives. It showed no cross-reactivity with other POMC-derived peptides such as $\beta \mathrm{E}_{1-16}, \beta \mathrm{E}_{1-17}$, des-tyrosine $\beta \mathrm{E}_{1-17}, \mathrm{ACTH}, \alpha-\mathrm{MSH}$, or $\gamma$-melanotropin, or with other non-POMC-derived opioid peptides [e.g., Leu-enkephalin, Met-enkephalin, dynorphin (DYN) A, dynorphin B, $\alpha$ - neoendorphin]. Sensitivity of the assay under equilibrium conditions was $2-3 \mathrm{fmol} /$ tube, with an $\mathrm{IC}_{50}$ of $\sim 20 \mathrm{fmol} /$ tube.

\section{Gel chromatography}

Gel filtration chromatography followed by $\beta \mathrm{E}$ RIA was performed on pooled samples from different experimental groups. After aliquots were removed for assay of total $\beta \mathrm{E}-\mathrm{ir}$, pooled extracts of two to three animals from each of the treatment groups were subjected to gel filtration chromatography to separate $\beta \mathrm{E}$-ir peptides on the basis of molecular weight. Chromatography was performed on a $1.5 \times 90-\mathrm{cm}$ Sephadex G-50-50 column developed with $1 \%$ formic acid containing $0.01 \%$ BSA. Fractions $(1.35 \mathrm{ml})$ were collected and vacuum dried for later assay of $\beta \mathrm{E}-\mathrm{ir}$. The column was precalibrated with blue dextran, camel $\beta$-LPH, camel $\beta \mathrm{E}_{1-31}$, camel $\beta \mathrm{E}_{1-27}$, and cobalt chloride.

\section{POMC mRNA quantitation}

POMC mRNA in individual hypothalami was quantitated by RNase protection and/or northern assays. For both techniques, radiolabeled antisense cRNA POMC probe was produced by transcribing a linearized pGEM4 plasmid containing a rat POMC cDNA insert (courtesy of Dr. J. Eberwine), which corresponded to the last 35 bases of intron $B$ and the first 395 bases of exon 3 of rat POMC (coding for amino acids $19-150$ of the protein precursor). Transcription was performed as described in Promega's technical bulletin (Madison, WI, U.S.A.), using $\left[\alpha-{ }^{32}\right.$ P $]$ UTP as the radioactive label and T7 RNA polymerase.

RNase protection assay. Radiolabeled POMC CRNA was mixed with aliquots of extracted RNA in hybridization buffer $\left[40 \mathrm{~m} M\right.$ piperazine- $N, N^{\prime}$-bis(2-ethanesulfonic acid), pH 6.4, $400 \mathrm{~m} M \mathrm{NaCl}, 1.0 \mathrm{~m} M$ EDTA] and deionized formamide $(50 \%)$. The mixture was denatured for $5 \mathrm{~min}$ at $90^{\circ} \mathrm{C}$, then incubated at $50^{\circ} \mathrm{C}$ for $14-18 \mathrm{~h}$. Unhybridized singlestranded RNA was digested by ribonuclease A (no. R-5125, Sigma, St. Louis, MO, U.S.A.; $10 \mathrm{mg} / \mathrm{ml}$ in RNase buffer, as follows: $10 \mathrm{~m} M$ Tris- $\mathrm{HCl}, \mathrm{pH} 7.5,5.0 \mathrm{~m} M$ EDTA, $0.2 M$ $\mathrm{NaCl}, 0.1 \mathrm{MLiCl}$ ) at $22^{\circ} \mathrm{C}$ for $\sim 60 \mathrm{~min}$. RNase activity was halted by adding proteinase $\mathrm{K}(40 \mathrm{mg} / \mathrm{ml})$ in $1 \%$ SDS and incubating at $37^{\circ} \mathrm{C}$ for $30 \mathrm{~min}$. Protected cRNA:mRNA hybrids were precipitated in ethanol containing $5 \mathrm{M}$ ammonium acetate and fractionated by electrophoresis on $4 \%$ polyacrylamide nondenaturing gels in TBE buffer $(89 \mathrm{~m} M$ Tris, $89 \mathrm{~m} M$ boric acid, $2 \mathrm{~m} M$ EDTA). The gels were exposed via direct contact autoradiography on Kodak XOMAT AR 5 film and individual bands were quantitated by determining their total integrated optical density using a Loats Image Analysis System (Westminster, MD, U.S.A.).

Northern analysis. Aliquots of total RNA from arcuate nuclei of individual animals were electrophoresed on $1.5 \%$ agarose gels with a HEPES-EDTA/6\% formaldehyde running buffer. RNA was passively transferred to Nytran filters (Schleicher and Schuell, Keene, NH, U.S.A.) and air dried. Filters were hybridized in buffer ( $5 \%$ SDS, $400 \mathrm{mM} \mathrm{NaPO}_{4}$, $1 \mathrm{mM}$ EDTA, $1 \% \mathrm{BSA}, 50 \%$ formamide) containing the radiolabeled POMC cRNA probe at $60^{\circ} \mathrm{C}$ for $20 \mathrm{~h}$, washed three times in $0.1 \times \mathrm{SSC}(15 \mathrm{mM}$ sodium chloride, $1.5 \mathrm{mM}$ sodium citrate), $0.1 \% \mathrm{SDS}, 1 \mathrm{~m} M$ EDTA at $70^{\circ} \mathrm{C}$ and exposed to X-ray film (Kodak X-OMAT AR5).

\section{Statistics}

Analyses of variance were performed to assess overall effects of NTX, and post hoc paired comparisons were evalu- 
A.

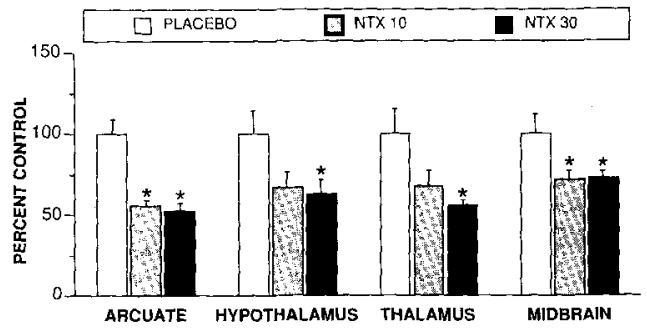

B.

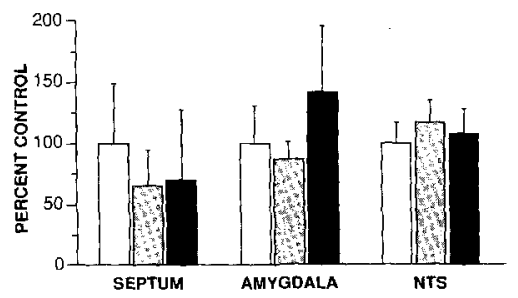

c.

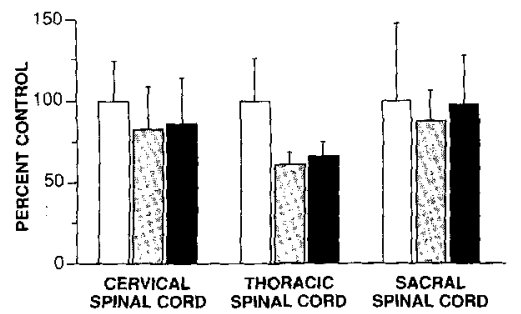

FIG. 1. Effects of chronic NTX pelleting on total $\beta E$-ir in different brain and spinal cord regions. Rats were implanted with two NTX (10 or $30 \mathrm{mg}$ ) or placebo pellets for 8 days, then decapitated. Different CNS areas were dissected and assayed for total $\beta E$-ir by an antibody that recognized the amino acid sequence of $\beta E_{17-27}$ (i.e., all $\beta$ E-ir species were detected). NTX significantly decreased $\beta E$-ir concentrations in the diencephalon and midbrain (A), but had no effect on other brain (B), or spinal cord (C) regions. Values, expressed as a percentage of mean placebo concentrations (see Results), represent mean \pm SEM from seven to eight animals. ${ }^{*} p$ $<0.05$, compared with the placebo-treated control group.

ated by Duncan's tests. In all cases, a significance level of 0.05 was used.

\section{RESULTS}

\section{Total $\beta \mathrm{E}$-ir concentrations}

Concentrations of total $\beta \mathrm{E}$-ir varied as a function of the CNS region examined. Basal levels in placebotreated animals were highest in the arcuate nucleus, extraarcuate hypothalamus, and septum $(92.6 \pm 9.1$, $97.8 \pm 14.4$, and $153.2 \pm 75.3 \mathrm{fmol} / \mathrm{mg}$ of tissue, respectively), and lowest in the spinal cord (3.8 \pm 1.1 , $3.6 \pm 1.1$, and $4.2 \pm 2.0 \mathrm{fmol} / \mathrm{mg}$ of tissue in the CSC, TSC, and LSC, respectively). $\beta \mathrm{E}$-ir concentrations ( $\mathrm{fmol} / \mathrm{mg}$ of tissue) in other brain regions were intermediate in value, as follows: thalamus (25.9 \pm 4.0 ), midbrain (12.7 \pm 1.7$)$, amygdala (7.9 \pm 2.4$)$, and NTS $(9.1 \pm 1.9)$. Chronic NTX treatment altered total $\beta \mathrm{E}-$ ir concentrations in a region-specific manner, with rostral regions generally showing decreases in peptide levels, whereas more caudal areas remained unchanged. NTX caused significant reductions (30$40 \%)$ in total $\beta \mathrm{E}-\mathrm{ir}$ in the arcuate nucleus $\left(F_{2,20}\right.$ $=18.9, p<0.0001)$, extraarcuate hypothalamus $\left(F_{2,21}\right.$ $=5.4, p<0.05)$, thalamus $\left(F_{2.15}=4.6, p<0.05\right)$, and midbrain $\left(F_{2,18}=4.7, p<0.05\right)$ compared with placebo controls (Fig. 1A). A similar decrease was also observed in the septum, but due to the large variability, this reduction did not differ significantly from control values. Other areas in which NTX had no significant effect on $\beta \mathrm{E}$-ir concentrations were the amygdala and NTS (Fig. 1B) as well as all three levels of the spinal cord (i.e., CSC, TSC, LSC; Fig. 1C). It should be noted that the two doses of NTX used in this study caused comparable changes in $\beta E$-ir levels, that is, the effects were not dose dependent. The effect of NTX did not appear to be specific to its route of administration, i.e., repeated daily injections or chronic infusion of NTX caused reductions in $\beta \mathrm{E}$-ir content in the hypothalamus similar to those found after pelleting (Fig. 2). Also similar to the pelleting results, the three doses of NTX used in the injection study produced consistent $35-40 \%$ decreases in $\beta \mathrm{E}$-ir peptide levels [Dunnett's $t=4.5,4.1$, and 4.2 (all $p<0.05$ ) for placebo versus the 2,10 , and $20 \mathrm{mg} / \mathrm{kg}$ doses, respectively; Fig. 2].

\section{Chromatographic separation of different $\beta \mathrm{E}$-ir peptides}

Analyses of brain extracts by molecular sieving and RIA revealed that total $\beta \mathrm{E}$-ir was composed of three distinguishable molecular weight species corresponding to $\beta-\mathrm{LPH}, \beta \mathrm{E}_{1-31}$, and $\beta \mathrm{E}_{1-27} / \beta \mathrm{E}_{1-26}\left(\beta \mathrm{E}_{1-27}\right.$ and $\beta \mathrm{E}_{1-26}$ could not be resolved from each other on this

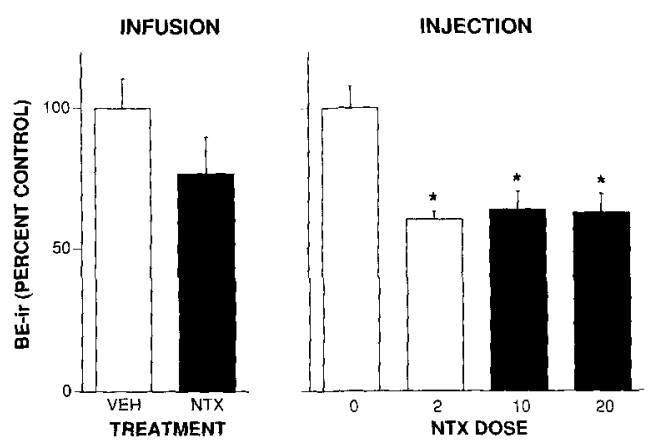

FIG. 2. Chronic infusion or repeated injections of NTX reduced total $\beta \mathrm{E}$-ir concentrations in the hypothalamus. In one experiment, animals implanted with osmotic minipumps were infused with NTX $(70 \mathrm{mg} / \mathrm{ml})$ or water at a rate of $1 \mu \mathrm{l} / \mathrm{h}$ for 8 days (left). In a separate experiment, rats received once daily subcutaneous injections of NTX $(2,10$, or $20 \mathrm{mg} / \mathrm{kg})$ or saline for 7 days and were killed $24 \mathrm{~h}$ after the last injection (right). After decapitation, hypothalami were dissected and assayed for total $\beta E$-ir. Values represent the mean \pm SEM from six animals and are expressed as a percentage of control levels $(174.0 \pm 18.4$ and 158.1 \pm 12.4 $\mathrm{fmol} / \mathrm{mg}$ of tissue for infusion and injection experiments, respectively). ${ }^{*} p<0.05$, compared with the control group. 

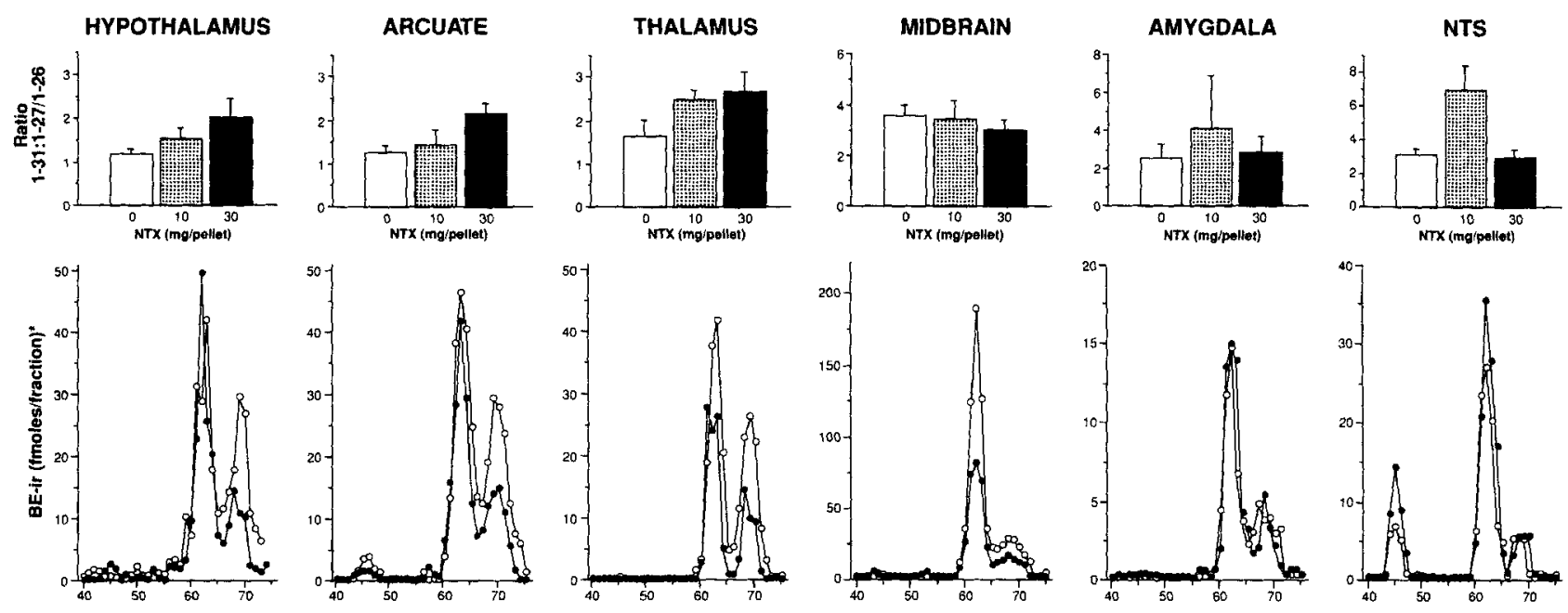

FIG. 3. Effects of chronic NTX pelleting on different $\beta E$-ir peptides in rat brain. Bottom: Representative chromatographs from different brain regions depicting changes in $\beta E$-ir peptide processing after 8 days of placebo $(O--O)$ or $30-m g ~ N T X(--\infty)$ pelleting. Pooled peptide extracts from different brain regions were loaded on Sephadex G-50-50 columns and developed with 1\% formic acid containing $0.01 \%$ BSA. Fractions $(1.3 \mathrm{ml})$ were collected and assayed for $\beta \mathrm{E}$-ir. Peptide standards for $\beta-\mathrm{LPH}, \beta \mathrm{E}_{1-31}$, and $\beta \mathrm{E}_{1-27}$ eluted at fractions 43-47, 59-65, and 64-71, respectively. Under these chromatographic conditions, $\beta \mathrm{E}_{1-26}$ coeluted with $\beta \mathrm{E}_{1-27}$. In addition, the peaks for $\beta \mathrm{E}_{1-31}$ and $\beta \mathrm{E}_{1-27} / \beta \mathrm{E}_{1-26}$ contained their $N$-acetylated derivatives (although acetylated $\beta \mathrm{E}$-ir peptides represent only minor components of all brain regions examined except for the NTS). Top: Effects of chronic NTX pelleting on the relative concentrations of $\beta E_{1-31}$ and $\beta \mathrm{E}_{1-27} / \beta \mathrm{E}_{1-26}$ peptides. Total immunoreactivity associated with the $\beta \mathrm{E}_{1-31}$ and $\beta \mathrm{E}_{1-26} / \beta \mathrm{E}_{1-27}$ peaks was calculated and data are expressed as the ratio of $\beta \mathrm{E}_{1-31}$ to $\beta \mathrm{E}_{1-26} / \beta \mathrm{E}_{1-27}$ concentrations. Values shown represent the mean $\pm \mathrm{SEM}$ of three separate chromatographs (for the arcuate and extraarcuate hypothalamus) or the mean and range of two chromatographic runs (all other brain regions). $\beta \mathrm{E}_{1-31}$ to $\beta \mathrm{E}_{1-27} /$ $\beta E_{1-26}$ ratios tended to rise in a dose-dependent manner after NTX pelleting in the three diencephalic brain regions.

column; Fig. 3). In addition, the $N$-acetylated derivatives of $\beta \mathrm{E}_{1-31}, \beta \mathrm{E}_{1-27}$, and $\beta \mathrm{E}_{1-26}$ would coelute with their respective precursor peptides. However, it should be kept in mind that, except for the NTS, $N$ - acetylated $\beta \mathrm{E}-\mathrm{ir}$ peptides normally comprise only a small proportion of the total $\beta \mathrm{E}$-ir in the brain areas examined (Zakarian and Smyth, 1982; Emeson and Eipper, 1986). $\beta \mathrm{E}$-ir associated with each of the three

TABLE 1. Effects of chronic NTX treatment on absolute amounts (femtomoles) of different sized $\beta E$-ir peptides in various brain regions

\begin{tabular}{lclcc}
\hline & Dose & $\beta$-LPH (\%) & $\beta \mathrm{E}_{1-31}(\%)$ & $\beta \mathrm{E}_{1-27} / \beta \mathrm{E}_{1-26}(\%)$ \\
\hline Arcuate $(\mathrm{n}=3)$ & 0 & $8.4 \pm 1.8$ & $170.2 \pm 18.6$ & $133.3 \pm 1.3$ \\
& 10 & $4.3 \pm 2.1(51)$ & $105.4 \pm 13.8(62)^{a}$ & $76.8 \pm 11.2(58)^{a}$ \\
Hypothalamus $(\mathrm{n}=3)$ & 30 & $5.8 \pm 1.4(69)$ & $116.1 \pm 10.9(68)$ & $55.1 \pm 8.5(41)^{a}$ \\
& 0 & $6.8 \pm 0.9$ & $160.5 \pm 10.2$ & $134.8 \pm 4.5$ \\
Thalamus $(\mathrm{n}=2)$ & 10 & $5.1 \pm 1.7(75)$ & $108.1 \pm 26.1(67)$ & $68.0 \pm 7.0(52)^{a}$ \\
& 30 & $7.0 \pm 1.9(103)$ & $101.8 \pm 26.1(64)$ & $48.2 \pm 4.3(37)^{a}$ \\
& 0 & $0.5 \pm 0$ & $130.7 \pm 2.7$ & $83.1 \pm 16.7$ \\
Midbrain $(\mathrm{n}=2)$ & 10 & $1.3 \pm 0.5(260)$ & $147.3 \pm 3.2(113)$ & $59.2 \pm 3.3(71)$ \\
& 30 & $0.8 \pm 0.8(160)$ & $90.2 \pm 3.5(69)$ & $34.5 \pm 4.5(41)$ \\
& 0 & $9.8 \pm 1.8$ & $460.8 \pm 89.7$ & $126.0 \pm 11.2$ \\
Amygdala $(\mathrm{n}=2)$ & 10 & $6.9 \pm 0.6(70)$ & $250.5 \pm 10.3(54)$ & $76.0 \pm 18.5(60)$ \\
& 30 & $8.5 \pm 0.1(87)$ & $273.4 \pm 7.4(59)$ & $90.8 \pm 9.1(72)$ \\
NTS $(\mathrm{n}=2)$ & 0 & $\mathrm{ND}$ & $113.3 \pm 29.3$ & $43.9 \pm 0.6$ \\
& 10 & $\mathrm{ND}$ & $114.0 \pm 6.0(101)$ & $52.0 \pm 36.2(118)$ \\
& 30 & 0 & $111.9 \pm 22.1(99)$ & $44.5 \pm 20.0(101)$ \\
& 10 & $19.4 \pm 3.2$ & $100.3 \pm 9.5$ & $23.6 \pm 6.6$ \\
& 30 & $18.9 \pm 8.2(152)$ & $123.5 \pm 5.4(123)$ & $16.5 \pm 2.8(70)$ \\
& & $101.6 \pm 7.4(101)$ & $29.6 \pm 4.8(125)$ \\
\hline
\end{tabular}

The percentage of total immunoreactivity associated with each of the three peaks observed after gel filtration chromatography (see Fig. 3) was determined for all brain regions examined and then was corrected for the $\beta \mathrm{E}$-ir concentrations determined in crude extracts. Values represent the mean \pm SEM for $n=3$ (arcuate and extraarcuate hypothalamus) or the mean and range for $n=2$ (all other brain regions) independent chromatographs. Statistical analyses were performed only on tissues with three samples. ND, not detected.

${ }^{a} p<0.05$ compared with the appropriate 0 -dose (placebo) group. 
A.

B.

Northern

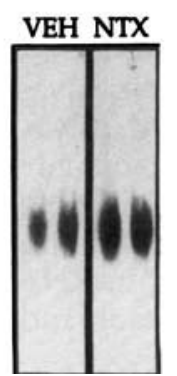

RNase Protection

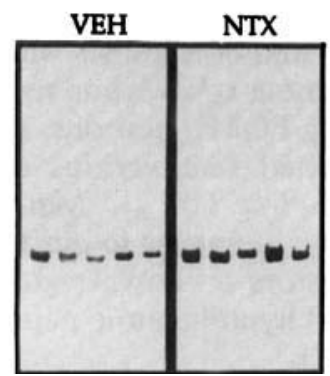

FIG. 4. Increase in hypothalamic POMC MRNA levels after chronic NTX infusion as revealed by northern (A) or RNase protection (B) analyses. For northern analyses, total RNA was extracted from individual hypothalami and electrophoresed on a $1.5 \%$ agarose/formaldehyde gel. After transfer to Nytran filters, membranes were probed with a radiolabeled POMC cRNA complementary to 35 bases of intron $B$ and 395 bases of exon 3 and then washed. Membranes were exposed to $x$-rays for several days at $-80^{\circ} \mathrm{C}$ with one intensifying screen. For the RNase protection assay, aliquots of total RNA from the same pools used in the northern analyses were hybridized with the radiolabeled POMC riboprobe. After digestion of single-stranded RNAs by RNase treatment, samples were electrophoresed on $4 \%$ nondenaturing polyacrylamide gels and exposed to $x$-rays for 8-24 $h$ at $-80^{\circ} \mathrm{C}$ with one intensifying screen.

peaks was calculated for each brain region and experimental treatment. In addition, the amount of the $\beta \mathrm{E}_{1-31}$ peak was calculated relative to the $\beta \mathrm{E}_{1-27} / \beta \mathrm{E}_{1-26}$ peak as a means of estimating changes in opioid agonist to antagonist/nonagonist activity, respectively. In diencephalic areas, chronic NTX treatment generally decreased the amounts of different POMC-derived peptides (Table 1; Fig. 3). Immunoreactivity associated with the $\beta \mathrm{E}_{1-31}$ peak was decreased by both NTX doses to $\sim 65 \%$ of control levels in the arcuate, extraarcuate hypothalamus, and thalamus, whereas the $\beta \mathrm{E}_{1-27} / \beta \mathrm{E}_{1-26}$ peak decreased $\sim 40 \%$ and $\sim 60 \%$ with the 10- and 30-mg NTX pelleting, respectively (Table 1). The relatively larger reductions in $\beta \mathrm{E}_{1-27}$ $\beta \mathrm{E}_{1-26}$ levels caused the ratios of $\beta \mathrm{E}_{1-31}$ to $\beta \mathrm{E}_{1-27} /$ $\beta \mathrm{E}_{1-26}$ to increase in the arcuate, extraarcuate hypothalamus, and thalamus; maximal effects were observed with the $30-\mathrm{mg}$ NTX pellets, where ratios increased approximately twofold (Fig. 3). In the midbrain, 10 - or $30-\mathrm{mg}$ NTX pellets caused proportionately similar decreases in the $\beta \mathrm{E}_{1-31^{-}}$and $\beta \mathrm{E}_{1-27} /$ $\beta \mathrm{E}_{1-26}$-size peaks, with the result that $1-31$ to $1-27 / 1-$ 26 ratios did not change (Table 1; Fig. 3). In the amygdala, NTX had no effect on any of the $\beta E$-ir species.

Caudal POMC structures also seemed unaffected by NTX pelleting. In the NTS, the amounts of different $\beta E$-ir peptides and their ratios were comparable in placebo- and NTX-treated animals (Table 1; Fig. 3). In addition, there did not appear to be any effect of NTX on $\beta E$ processing in any spinal cord region (data not shown). However, the latter data can be consid-

ered preliminary because the limited amount of $\beta \mathrm{E}$-ir in the spinal cord allowed us to perform chromatographic analyses only once per region.

\section{POMC mRNA quantitation}

POMC MRNA in the arcuate nucleus was quantitated in three separate studies that differed primarily in NTX's route of administration (i.e., via pelleting, continuous infusion, or repeated intraperitoneal injections). In most cases, POMC mRNA in individual samples was quantitated by both northern and RNase protection analyses. Data from the continuous infusion experiment illustrate that the two techniques generally yielded comparable results (Fig. 4). Autoradiographic bands from the northern analyses were quantitated by optical densitometry and the data from each of the three studies are shown in Fig. 5. With all three routes of administration, POMC mRNA levels in NTX-treated animals were $30-40 \%$ higher than those found in control animals, although the increases reached statistical significance only in the pelleting $\left(F_{2,8}=5.9, p<0.05\right)$ and osmotic minipump $\left(t_{10}\right.$ $=2.5, p<0.05$ ) experiments.

\section{DISCUSSION}

The following were the three main findings in these studies: (1) NTX appeared to up-regulate $\beta \mathrm{E}$ biosynthesis and release in arcuate POMC neurons, as evidenced by decreases in $\beta \mathrm{E}$-ir concentrations and increases in POMC mRNA levels. (2) The effects of NTX on POMC biosynthesis were region specific. Whereas arcuate POMC cells were apparently up-regulated, NTX had no effect on $\beta E$-ir peptides in the NTS or spinal cord. Within the rostral POMC system itself, there were regional differences in the effects of NTX. (3) Chronic NTX treatment appeared to increase $\beta \mathrm{E}_{1-31}$ to $\beta \mathrm{E}_{1-27} / \beta \mathrm{E}_{1-26}$ ratios in diencephalic

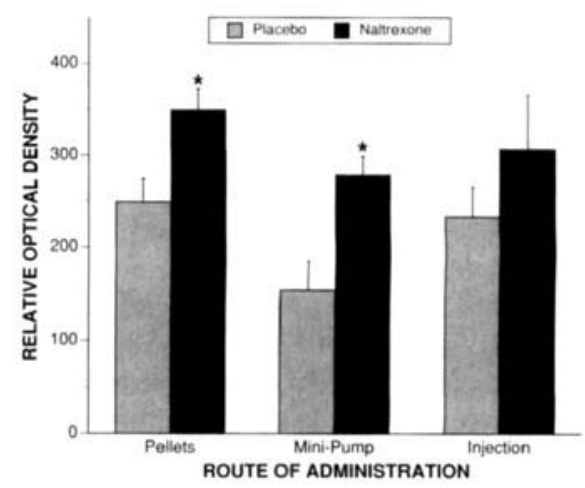

FIG. 5. Effects of chronic NTX treatment on POMC mRNA levels in the arcuate/hypothalamus. NTX was administered to animals by pellets $(10 \mathrm{mg} /$ pellet $)$, osmotic minipump $(70 \mu \mathrm{g} / \mathrm{h})$, or repeated injections $(10 \mathrm{mg} / \mathrm{kg})$ as described in the legends for Figs. 1 and 2. Total RNA from individual animals was processed by northern analysis and specific POMC mRNA bands were quantitated by densitometry. Data represent the mean $( \pm S E M)$ relative optical density of six to eight animals. " $p<0.05$, compared with the placebo-treated control group. 
brain areas. We speculate that these shifts in peptide forms could represent a novel regulatory mechanism of POMC cells whereby changes in opioid tone could be effected by cleaving the opioid agonist $\beta E_{1-31}$ to an antagonist form $\left(\beta \mathrm{E}_{1-27}\right)$.

First, in agreement with previous results (Ragavan et al., 1983), we found that NTX markedly reduced total $\beta \mathrm{E}$-ir concentrations to approximately twothirds of control levels in most rostral brain regions examined. It is important to note that steady-state measures of peptide concentrations reflect an equilibrium between the rates of peptide biosynthesis and peptide release. Hence, in the absence of other information, it is impossible to know whether NTX treatment lowered $\beta \mathrm{E}$-ir levels by increasing the rate of peptide release or degradation or by decreasing $\beta \mathrm{E}$ biosynthesis. Results from a second measure of biosynthetic activity, showing that POMC mRNA levels were elevated in NTX-treated animals, suggest that overall biosynthesis of $\beta \mathrm{E}$ was stimulated by chronic NTX treatment. Presumably, these increases in arcuate POMC mRNA represent a compensatory response to increased peptide release. That steady-state $\beta \mathrm{E}$-ir concentrations were reduced at the same time that POMC mRNA levels were increased could be explained if the biosynthetic rate had not yet adequately compensated for the increased rate of peptide release. We have interpreted the pattern of changes in $\beta \mathrm{E}$ peptide and POMC mRNA concentrations as indicating that NTX activates POMC neurons in the arcuate nucleus, stimulating both $\beta \mathrm{E}$ release and biosynthesis. The present data complement well the results of earlier studies, which suggest that chronic morphine treatment inhibits $\beta \mathrm{E}$ release and biosynthesis in the hypothalamus (Mocchetti and Costa, 1986; Mocchetti et al., 1989; Bronstein et al., 1990). The present results, showing that an opiate antagonist apparently induces $\beta \mathrm{E}$ biosynthesis, suggest that POMC neurons in the arcuate nucleus are tonically inhibited by endogenous opioids.

It is interesting that the effects of opiate agonists and antagonists on POMC biosynthesis are similar to those reported for the two other opioid peptide families, prodynorphin (Pro-DYN) and proenkephalin. Previous studies have demonstrated that chronic morphine treatment down-regulates (Uhl et al., 1988), and chronic NTX up-regulates (Tempel et al., 1990), enkephalin biosynthesis in the striatum. Similarly, striatal Pro-DYN mRNA has been found to decrease after chronic morphine exposure and increase after chronic naloxone treatment (Romualdi et al., 1990, 1991). Thus, it appears that all three opioid peptide families are regulated in a similar fashion by opiate agonist or antagonist treatment. Romualdi's group has further shown that the effects of chronic treatment with $\kappa$-opioid receptor agonists (ethylketocyclazocine or U50,488H) on Pro-DYN message are comparable with those found with morphine (Romualdi et al., 1990), suggesting that $k$-receptor-selec- tive endogenous ligands, such as DYN A (Chavkin et al., 1982; Spampinato and Candeletti, 1985), might be involved in regulating the activity of DYN neurons. Experiments using specific opiate receptor agonists and antagonists will help in determining the endogenous opioids and receptor types involved in regulating POMC neurons. In this regard, it was recently reported that various endogenous opioid peptides (including $\beta \mathrm{E}_{1-31}$, Met- and Leu-enkephalin, and DYN $_{1-8}$ ) appear to act via $\delta-, \kappa_{-}$, and $\sigma-$ (but not $\mu$-) receptors to down-regulate POMC mRNA in cultured hypothalamic neurons (l'Hereault and Barden, 1991).

The second major point derived from these studies relates to NTX causing region-specific changes in $\beta \mathrm{E}$ biosynthesis. To begin with, not all brain areas innervated by arcuate POMC neurons responded in the same manner to chronic NTX treatment. In terms of total $\beta \mathrm{E}$-ir, the amygdala was conspicuous in showing no effects of NTX, whereas other rostral brain regions exhibited $30-40 \%$ decreases in $\beta \mathrm{E}$-ir. Because of the high variability in the septum data, it was unclear whether this region was also affected by NTX pelleting. Until future studies resolve this point, the septum and amygdala may be viewed as unique among rostral POMC regions in that they appear to be unaffected by chronic NTX treatment. The effects of NTX on the relative concentrations of $\beta \mathrm{E}_{1-31}$ and $\beta \mathrm{E}_{1-27} / \beta \mathrm{E}_{1-26}$ also appear to be region specific. Whereas $\beta \mathrm{E}_{1-31}$ to $\beta \mathrm{E}_{1-27} / \beta \mathrm{E}_{1-26}$ ratios tended to increase dose dependently in diencephalic areas, this was not the case in the midbrain, even though this area had a reduction in total $\beta \mathrm{E}$-ir similar to that seen in the arcuate, hypothalamus, or thalamus. One explanation for regionspecific effects of NTX within the rostral POMC system is that there may be anatomically distinct subpopulations of arcuate POMC neurons, some of which project to diencephalic areas and others which project to the midbrain, septum, and/or amygdala. These different POMC pathways may then be differentially regulated by NTX. There are anatomical and pharmacological data that directly or indirectly suggest that subsets of arcuate POMC cells can be defined in terms of unique nerve terminal projections, regulation, or function (Wilcox et al., 1986; Yoshida and Taniguchi, 1988; Bronstein and Akil, 1989). Alternatively, it could be postulated that opioid ligands regulate $\beta \mathrm{E}-\mathrm{ir}$ peptide release and/or processing presynaptically and that the region-specific effects observed after NTX are due to differences in the opioid inputs into different POMC nerve terminal regions. Unfortunately, the anatomical data do not distinguish between these possibilities at the present time. Three major fiber projectional systems (rostral, lateral, and caudal) have been described for POMC perikarya in the arcuate nucleus (Khachaturian et al., 1985). With the possible exception of the septum, every POMC nerve terminal area in the CNS may be innervated by at least two of these pathways. Regardless of the mechanism, however, the 
present data reinforce the notion that the arcuate POMC cell group is not a homogeneous system.

The present results suggest that, in general, rostral and caudal POMC systems are differentially affected by chronic opiate antagonist treatment. Although several rostral brain structures showed a change in at least one aspect of POMC biosynthesis, the NTS and all three levels of the spinal cord appeared to be unaffected by NTX. (We should note that NTX did reduce total $\beta \mathrm{E}$-ir in the TSC by $\sim 40 \%$, but this difference was not statistically significant because of high variance in the placebo group.) Previous studies have demonstrated that the rostral arcuate-derived POMC system is anatomically separate from caudal POMC neurons (although the converse is not equally true as some $\beta \mathrm{E}$-ir nerve terminals in the medulla are derived from arcuate neurons) (Palkovits and Eskay, 1987; Palkovits et al., 1987; Joseph and Michael, 1988). The present data, showing rostral-caudal differences in the effects of NTX on $\beta E$ biosynthesis, suggest that not only are rostral and caudal POMC systems anatomically distinct, they may also be regulated in neurochemically different ways. Although the present data demonstrate that the NTS and spinal cord were similarly insensitive to NTX's effects, these two areas have been previously shown to differ in their response to chronic opiate agonist treatment. Consistent increases in total $\beta \mathrm{E}$-ir were observed throughout the spinal cord after 7 days of morphine treatment; at the same time, $\beta \mathrm{E}$-ir levels in the NTS remained unchanged (Gutstein et al., 1990; Bronstein et al., in preparation). Taken together with the results of these studies, the data suggest that although $\beta \mathrm{E}$-ir peptide levels in the spinal cord can be altered by opioid agonists, they do not appear to be tonically inhibited by endogenous opioids (in contrast to arcuate POMC neurons).

The unique pattern of effects of opiate agonists and antagonists on $\beta \mathrm{E}$ peptides in the spinal cord provides support for the idea that there may be intrinsic POMC neurons in the spinal cord. Gianoulakis and Angelogianni (1989) have shown that the mixture of $\beta \mathrm{E}$-ir peptides in the spinal cord is unique in the CNS (i.e., POMC appears to undergo far less processing than in more rostral CNS regions). Recent data in our laboratory, showing that some $\beta E$-ir remains in thoracic and sacral segments of the spinal cord even after complete transection at higher spinal cord levels, further support the possibility of intrinsic POMC neurons in the spinal cord (Gutstein et al., 1992). The finding that the opiate regulation of $\beta \mathrm{E}$-ir peptides in the spinal cord may differ from the arcuate or NTS POMC systems is consistent with the idea that some POMC somata exist in the spinal cord. It should be pointed out, however, that this idea is not supported by immunocytochemical data, which revealed the presence of POMC peptide-containing nerve fibers and terminals, but no cell bodies, in the spinal cord of the adult rat (Khachaturian et al., 1985; Tsou et al., 1986).
One of the most intriguing observations in these experiments was the apparent change in the relative concentrations of $\beta \mathrm{E}_{1-31}$ and $\beta \mathrm{E}_{1-27} / \beta \mathrm{E}_{1-26}$ after chronic NTX pelleting. The ratio of these peptides provides an estimate of the relative amounts of opioid agonist and antagonist/nonagonist in different brain regons. In the arcuate, extraarcuate hypothalamus, and thalamus, $\beta \mathrm{E}_{1-31}$ to $\beta \mathrm{E}_{1-27} / \beta \mathrm{E}_{1-26}$ ratios increased as a result of proportionately larger NTX-induced decreases in $\beta \mathrm{E}_{1-27} / \beta \mathrm{E}_{1-26^{-}}$versus $\beta \mathrm{E}_{1-31}$-size peptides. Maximal effects, produced by the $30-\mathrm{mg}$ pellets, resulted in $1-31$ to $1-27 / 1-26$ ratios nearly doubling. An interesting question is whether the higher ratios result from changes in $\beta \mathrm{E}$-ir processing or, perhaps, to peptide-selective changes in degradation or release. Regardless of the mechanism, alterations in the relative concentrations of differently processed $\beta \mathrm{E}$-ir peptides could have important functional consequences because each peptide form has unique pharmacologi$\mathrm{cal} /$ physiological properties (see Young et al., 1992). For example, although $\beta \mathrm{E}_{1-31}$ possesses classical opiate-like properties, $\beta \mathrm{E}_{1-27}$ appears to act as an endogenous antagonist of many of the effects of $\beta \mathrm{E}_{1-31}$. In addition to competing with $\beta \mathrm{E}_{1-31}$ for opiate binding sites (Akil et al., 1981), administration of $\beta \mathrm{E}_{1-27}$ attenuates or completely blocks the opioid actions of $\beta \mathrm{E}_{1-31}$ in a variety of paradigms including analgesia (Deakin et al., 1980; Hammonds et al., 1984), reinforcement (Bals-Kubik et al., 1988), Met-enkephalin release (Tseng and $\mathrm{Li}, 1986$ ), and cardiovascular responses (Hirsch et al., 1988, 1990). Because proteolysis of $\beta \mathrm{E}_{1-31}$ to $\beta \mathrm{E}_{1-27}$ changes the peptide from a receptor agonist to antagonist, even small changes in the relative concentrations of these two compounds could have profound effects on the amount of opioid signal transmitted across a synapse. Previously, morphine pelleting was found to decrease the $\beta \mathrm{E}_{1-31}$ to $\beta \mathrm{E}_{1-27} / \beta \mathrm{E}_{1-26}$ ratio, suggesting that endogenous opioid activity may have been functionally decreased (Bronstein et al., 1990b). The increase in $\beta \mathrm{E}_{1-31}$ to $\beta \mathrm{E}_{1-27} /$ $\beta E_{1-26}$ ratios observed here after chronic treatment with NTX implies that there may be greater opioid tone in diencephalic POMC nerve terminals of NTXtreated animals compared with control animals. There have been reports that animals treated chronically with opiate antagonists display hypersensitive responses in opioid-mediated functions such as analgesia (Bardo et al., 1984; Tempel et al., 1985; Yoburn et al., 1985). Although antagonist-induced up-regulation of opiate receptors is likely to play an important role in this increased sensitivity, the present data suggest that changes in endogenous opioid peptide forms may also contribute to this effect.

In summary, we found that chronic treatment with NTX altered several parameters of POMC biosynthesis in the rostral arcuate system, suggestive of an upregulation of $\beta \mathrm{E}$ biosynthesis and release in these neurons. In addition, NTX appeared to alter the relative amounts of opioid agonist and antagonist/nonagonist 
$\beta \mathrm{E}$-ir peptides in diencephalic areas such that endogenous opioid tone may have increased. In contrast to its effects on the arcuate POMC system, NTX caused no apparent changes in $\beta \mathrm{E}$-ir peptides in the NTS or spinal cord. Taken together with previous work, showing inhibitory effects of opiate agonists on $\beta E$ biosynthesis, the evidence suggests that endogenous opioids regulate the activity of a subpopulation of POMC neurons in the arcuate nucleus.

Acknowledgment: This work was supported in part by a Medical Research Council of Canada Postdoctoral Fellowship (D.M.B.), a Department of Anesthesiology Starter grant (H.B.G.), and a National Institute of Drug Abuse (NIDA) NRSA DA05336 (K.A.T.) and NIDA grant DA02265 (H.A.). We also thank NIDA for providing us with the naltrexone and placebo pellets, Dr. Alfred Mansour for donating tissue, and Dr. Jim Eberwine for giving us the rat POMC cDNA.

\section{REFERENCES}

Akil H., Watson S. J., Barchas J. D., and Li C. H. (1979) Beta-endorphin immunoreactivity in rat and human blood: radioimmunoassay, comparative levels, and physiological alterations. Life Sci. 24, 1659-1666.

Akil H., Young E., Watson S. J., and Coy D. (1981) Opiate binding properties of naturally occurring $\mathrm{N}$ - and $\mathrm{C}$-terminus modified beta-endorphin. Peptides 2, 289-292.

Akil H., Shiomi H., and Matthews J. (1985) Induction of the intermediate pituitary by stress: synthesis and release of a nonopioid form of beta-endorphin. Science 227, 424-426.

Bals-Kubik R., Herz A., and Shippenberg T. S. (1988) $\beta$-endorphin(1-27) is a naturally occurring antagonist of the reinforcing effects of opioids. Naunyn Schmiedebergs Arch. Pharmacol. 338, 392-396.

Bardo M. T., Miller J. S., and Risner M. E. (1984) Opiate receptor supersensitivity produced by chronic naloxone treatment: dissociation of morphine-induced antinociception and conditioned taste aversion. Pharmacol. Biochem. Behav. 21, 591597.

Bloch B., Bugnon C., Fellman D., and Lenys D. (1978) Immunocytochemical evidence that the same neurons in the human infundibular nucleus are stained with anti-endorphins and antisera of other related peptides. Neurosci. Lett. 10, 147-152.

Bloom F., Battenberg E., Rossier J., Ling N., and Guillemin R. (1978) Neurons containing beta-endorphin in rat brain exist separately from those containing enkephalin: immunocytochemical studies. Proc. Natl. Acad. Sci. USA 75, 1591-1595.

Bradbury A. F., Feldberg W. F., Smyth D. G., and Snell C. (1976) Lipotropin C-fragment: an endogenous peptide with potent analgesic activity. In: Opiates and Endogenous Opioid Peptides (Kosterlitz H., ed), pp. 63-70. Elsevier, Amsterdam.

Bronstein D. M. and Akil H. (1989) Effects of electrical stimulation in the periaqueductal gray on POMC peptides and mRNA in the rat brain. In: Prog. Clin. Biol. Res. (Quirion R., Jhamandas K., and Gianoulakis C., eds), pp. 219-222. Alan R. Liss, New York.

Bronstein D. M., Przewlocki R., and Akil H. (1990) Effects of morphine treatment on proopiomelanocortin systems in rat brain. Brain Res. 519, 102-111.

Bronstein D. M., Schafer M. K. H., Watson S. J., and Akil H. (1992) Evidence that $\beta$-endorphin is synthesized in the nucleus tractus solitarius: detection of POMC mRNA. Brain Res. (in press).

Cathala G., Savouret J. T., Mendez B., West B. L., Karin M., Mar- tial J. A., and Bexter J. D. (1983) A method for the isolation of intact, translationally active ribonucleic acid. DNA 2, 329335.

Chavkin C., James I. F., and Goldstein A. (1982) Dynorphin is a specific endogenous ligand of the kappa-opioid receptor. Science 215, 413-415.

Chretien M., Benjannet S., Dragon N., Seidah N. G., and Lis M. (1976) Isolation of peptides with opiate activity from sheep and human pituitaries: relationship to beta-LPH. Biochem. Biophys. Res. Commun. 72, 472-478.

Deakin J. F., Dostrovsky J. O., and Smyth D. (1980) Influence of $\mathrm{N}$-terminal acetylation and $\mathrm{C}$-terminal proteolysis on the analgesic activity of beta-endorphin. Biochem. J. 189, 501-506.

Dores R. M., Jain M., and Akil H. (1986) Characterization of the forms of $\beta$-endorphin and $\alpha-\mathrm{MSH}$ in the caudal medulla of the rat and guinea pig. Brain Res. 377, 251-260.

Emeson R. B. and Eipper B. A. (1986) Characterization of proACTH/endorphin-derived peptides in rat hypothalamus. $J$. Neurosci. 6, 837-849.

Gianoulakis C. and Angelogianni P. (1989) Characterization of $\beta$ endorphin peptides in the spinal cord of the rat. Peptides 10 , 1049-1054.

Gutstein H. B., Bronstein D. M., and Akil H. (1990) The effect of chronic morphine administration on spinal $\beta$-endorphin levels. Soc. Neurosci. Abstr. 16, 1026.

Gutstein H. B., Bronstein D. M., and Akil H. (1992) Beta-endorphin processing and cellular origins in rat spinal cord. Pain (in press).

Hammonds R. G. Jr., Nicolas P., and Li C. H. (1984) $\beta$-Endorphin$(1-27)$ is an antagonist of $\beta$-endorphin analgesia. Proc. Natl. Acad. Sci. USA 81, 1389-1390.

Hirsch M. D., Millington W. R., McKenzie J. E., and Mueller G. P. (1988) $\beta$-Endorphin-(1-27) is a potent endogenous hypotensive agent. Soc. Neurosci. Abstr. 14, 465.

Hirsch M. D., Villavicencio A. E., McKenzie J. E., and Millington W. R. (1990) C-terminal proteolysis modifies cardioregulation by $\beta$-endorphin. Soc. Neurosci. Abstr. 16, 1025.

Joseph S. A. and Michael G. J. (1988) Efferent ACTH-IR opiocortin projections from nucleus tractus solitarius: a hypothalamic deafferentation study. Peptides 9, 193-201.

Joseph S. A., Pilcher W. H., and Bennet-Clarke C. (1983) Immunocytochemical localization of ACTH perikarya in nucleus tractus solitarius: evidence for a second opiocortin neuronal system. Neurosci. Lett. 38, 221-225.

Khachaturian H., Lewis M. E., Tsou K., and Watson S. J. (1985) $\beta$-Endorphin, $\alpha-\mathrm{MSH}, \mathrm{ACTH}$, and related peptides. In: Handbook of Chemical Neuroanatomy, Vol 4: GABA and Neuropeptides in the CNS, Part I (Bjorklund A. and Hokfelt T., eds), pp. 216-272. Elsevier Science, Amsterdam.

l'Hereault S. and Barden N. (1991) Regulation of proopiomelanocortin messenger RNA concentrations by opioid peptides in primary cell cultures of rat hypothalamus. Mol. Brain Res. 10, 115-121.

Mains R. E., Eipper B. A., and Ling N. (1977) Common precursor to corticotropins and endorphins. Proc. Natl. Acad. Sci. USA 74, 3014-3017.

Mocchetti I. and Costa E. (1986) Down regulation of hypothalamic pro-opiomelanocortin system during morphine tolerance. Neuropharmacology 9(Suppl. 1), 125-127.

Mocchetti I., Ritter A., and Costa E. (1989) Down-regulation of pro-opiomelanocortin synthesis and beta-endorphin utilization in hypothalamus of morphine-tolerant rats. J. Mol. Neurosci. 1, 33-38.

Nakanishi S., Inoue A., Kita T., Nakamura M., Chang A. C. Y., Cohen S. N., and Numa S. (1979) Nucleotide sequence of cloned cDNA for bovine corticotropin-beta-lipotropin precursor. Nature 278, 423-425.

Nilaver G., Zimmerman E. A., Defendini R., Liotta A., Krieger D. A., and Brownstein M. (1979) Adrenocorticotropin and beta-LPH in hypothalamus. J. Cell Biol. 81, 50-58.

Palkovits M. and Eskay R. L. (1987) Distribution and possible ori- 
gin of $\beta$-endorphin and ACTH in discrete brainstem nuclei of rats. Neuropeptides 9, 123-137.

Palkovits M., Mezey E., and Eskay R. L. (1987) Pro-opiomelanocortin-derived peptides (ACTH/ $\beta$-endorphin/ $\alpha$-MSH) in brainstem baroreceptor areas of the rat. Brain Res. 436, 323328 .

Ragavan V. V., Wardlaw S. L., Kreek M. J., and Frantz A. G. (1983) Effect of chronic naltrexone and methadone administration on brain immunoreactive $\beta$-endorphin in the rat. Neuroendocrinology 37, 266-268.

Roberts J. L. and Herbert E. (1977a) Characterization of a common precursor to corticotropin and beta-lipotropin: cell-free synthesis of the precursor and identification of corticotropin peptides in the molecule. Proc. Natl. Acad. Sci. USA 74, 4826-4830.

Roberts J. L. and Herbert E. (1977b) Characterization of a common precursor to corticotropin and beta-lipotropin: identification of beta-lipotropin peptides and their arrangement relative to corticotropin in the precursor synthesized in a cell free system. Proc. Natl. Acad. Sci. USA 74, 5300-5304.

Romualdi P., Lesa G., and Ferri S. (1990) Chronic exposure to opioid agonists and an antagonist affects pro-dynorphin gene expression. In: New Leads in Opioid Peptide Research (van Ree J. M., Mulder A. H., Wiegant V. M., and van Wimersma Greidanus T. B., eds), pp. 146-147. Excerpta Medica, Amsterdam.

Romualdi P., Lesa G., and Ferri S. (1991) Chronic opiate agonists down-regulate prodynorphin gene expression in rat brain. Brain Res. 563, 132-136.

Schwartzberg D. G. and Nakane P. K. (1983) ACTH-related peptide containing neurons within the medulla oblongata of the rat. Brain Res. 276, 351-356.

Shiomi H., Watson S. J., Kelsey J. E., and Akil H. (1986) Pre-translational and post-translational mechanisms for regulating $\beta$ endorphin-adrenocorticotropin of the anterior pituitary lobe. Endocrinology 119, 1793-1799.

Spampinato S. and Candeletti S. (1985) Characterization of dynorphin-A-induced antinociception at the spinal level. Eur. $J$. Pharmacol. 110, 21-30.

Tempel A., Gardner E. L., and Zukin R. S. (1985) Neurochemical and functional correlates of naltrexone-induced opiate receptor up-regulation. J. Pharmacol. Exp. Ther. 232, 439-444.

Tempel A., Kessler J. A., and Zukin R. S. (1990) Chronic naltrexone treatment increases expression of preproenkephalin and preprotachykinin mRNA in discrete brain regions. $J$. Neurosci. 10, 741-747.

Tseng L. F. and Li C. H. (1986) Beta-endorphin (1-27) inhibits the spinal beta-endorphin-induced release of met-enkephalin. Int. J. Pept. Protein Res. 27, 394-397.

Tsou K., Khachaturian H., Akil H., and Watson S. J. (1986) Immunocytochemical localization of proopiomelanocortin-derived peptides in the adult rat spinal cord. Brain Res. 378, 28-35.

Uhl G. R., Ryan J. P., and Schwartz J. P. (1988) Morphine alters preproenkephalin gene expression. Brain Res. 458, 391-397.

Watson S. J., Barchas J. D., and Li C. H. (1977) Beta-lipotropin: localization in cells and axons in rat brain by immunocytochemistry. Proc. Natl. Acad. Sci. USA 74, 5155-5158.

Watson S. J., Richard C. W., and Barchas J. D. (1978) Adrenocorticotropin in rat brain: immunocytochemical localization in the cells and axons. Science 200, 1180-1182.

Wilcox J. N., Roberts J. L., Chronwall B. M., Bishop J. F., and O'Donohoe T. (1986) Localization of proopiomelanocortin mRNA in functional subsets of neurons defined by their axonal projections. I. Neurosci. Res. 16, 89-96.

Yoburn B. C., Goodman R. R., Cohen A. H., Pasternak G. W., and Inturrisi C. E. (1985) Increased analgesic potency of morphine and increased brain opioid binding sites in the rat following chronic naltrexone treatment. Life Sci. 36, 2325-2332.

Yoshida M. and Taniguchi Y. (1988) Projection of pro-opiomelanocortin neurons from the rat arcuate nucleus to the midbrain central gray as demonstrated by double staining with retrograde labeling and immunohistochemistry. Arch. Histol. Cytol. 51, 175-183.

Young E., Bronstein D. M., and Akil H. (1992) Pro-opiomelanocortin (POMC) biosynthesis, processing and secretion: functional implications. Handbook Exp. Pharmacol. (in press).

Zakarian S. and Smyth D. G. (1982) $\beta$-Endorphin is processed differently in specific regions of rat pituitary and brain. Nature 296, 250-252. 